\title{
Analysis of the Fusion and Collision of Chinese and Western Music and Culture from the Film Score of "The Last Emperor"
}

\author{
Yushang $\mathrm{Ni}^{1, \mathrm{a}}$ \\ ${ }^{1}$ Catalyst Institution of Creative Arts \& Technology, 12459, Berlin, Germany \\ alithiumnil77@gmail.com
}

\begin{abstract}
"The Last Emperor" is a classic movie portraying Chinese history from a Western perspective. The brilliant soundtrack of the movie shines out. It is a blend of Chinese and Western elements. Through the collision and fusion of Chinese and Western musical elements, the soundtrack promotes and presents the plot of the movie through music. It is a good theme for the research and analysis of the relationship between music and Chinese and Western social cultures. This article explores the aesthetic resonance of Chinese and foreign audiences by analysing the uniqueness of the soundtrack.
\end{abstract}

Keywords: Composition, Chinese and Western Fusion, Film Music, Ethnomusicology, "The Last Emperor"

\section{INTRODUCTION}

"The Last Emperor", is a historical film epic, it was directed by Italian director Bernardo Bertolucci in 1986. Due to the close cooperation between China, Italy, and Britain, and the integration of East and West, the film was critiqued as it "both embodies the vast and profound traditional civilization of China, and reflects the Eastern culture in the eyes of Western culture (MOUTON, 1992)." Overall, the film won 9 heavyweight awards, such as the Best Picture, the Best Director, and the Best Adapted Screenplay at the 60th Oscar Awards, and naturally also won the award for the best Oscar soundtrack. Three artists were involved in composing the film: Ryuichi Sakamoto from Japan, David Byrne from the United Kingdom, and Su Cong from China. Each one has different backgrounds and musical styles. However, the film captures the magical effect of fusing the Eastern and Western cultures. The artists composed a suitable soundtrack for this Chinese historical epic portrayed from the perspective of Westerners, in doing so, the artists were able to appropriately highlight the ups and downs of Aixinjueluo Puyi's life.

\section{EXPLORING THE FUSION AND COLLISION OF CHINESE AND WESTERN MUSIC IN THE FILM SOUNDTRACK OF "THE LAST EMPEROR"}

\subsection{The background and content of "The Last Emperor"}

Aixinjueluo Puyi, was born in 1906. He was the last emperor of the Qing Dynasty. In 1908, at the age of three Puyi inherited the throne in the palace. However, due to his very young age and lack of experience, Puyi became a puppet-like emperor (Kehr, 1999). It was during his era that saw the collapse of the Qing imperial family and dynasty. Following the collapse of the dynasty, the Republic of China was founded. At the same time, Puyi's nominal career as an emperor ended. Puyi was forced to leave the Forbidden City. Following this, he collaborated with the Japanese. In 1931, he established Manchukuo in the Northeast, he governed in collaboration with the Japanese, using the era-name of Datong (Ta-tung). He believed he could revive the former glory of the Qing Empire with the Japanese alongside him. However, at the end of World War II, Japan was defeated. Following Japan's defeat, the Soviet Union detained Japan as a war criminal of Manchukuo. In 1950, Manchukuo was handed over to the Chinese government. Puyi became a prisoner. Following ten years of reformation in Fushun War Criminals Administration, he was released by 
amnesty. In October 1967, Puyi passed away at the age of 61 years in Beijing. The reasons for his death were complications that arose from kidney cancer and heart disease (uraemia) (Storaro \& Rutter, 1989).

"The Last Emperor" spans half a century in time, and the film portrays most of the major events of Puyi's life. In addition, the film poetically explores the secrets of history (Chion, 1994). Moreover, the recurring theme song and its variations throughout the film also highlights the ups and downs in the lives of the characters. In addition, the theme song provides a three-dimensional perspective in relation to the inner state of struggle. The film touches the audience in a remarkable manner, it makes the audience feel consider the life course of the last emperor $\mathrm{Pu} \mathrm{Yi}$ in a deeper way in the context of the turbulent era in which Pu Yi lived (Clarke, 1988).

\subsection{Exploration of the theme song of "The Last Emperor"}

There are two theme songs for the last emperor, in addition to the "Last Emperor Theme" composed by Ryuichi Sakamoto, the "Main Title Theme" was composed by David Byrne. In the entire soundtrack collection, besides the composition by Su Cong, the two main creators also contributed half of the soundtrack to the entire movie. However, the artists have distinctly different styles (Thayer \& Levenson, 1983). Therefore, the works embody two very different styles. Similarly, there is an entirely different mood contained within the creation of the theme song. In a contrasting manner to the positive and cheerful music style of David Byrne, Sakamoto Ryuichi's soundtrack conveys sadness, and his work mostly appears during the scenes that depict the misfortunate that happens to Puyi and those around him (Burt, 1994)). The main aim of the present study is to analyse the theme song composed by Ryuichi Sakamoto.

There are two theme melodies in the "Last Emperor Theme". These two musical melodies run throughout the entire film. However, they are recreated with different instruments, speeds, rhythms, and textures, in such a way that it matches the mood of different scenes perfectly. The complete theme song containing the two theme melodies appears twice, in addition, the theme melodies also rendered the two climaxes of the entire play (Brown, 1988).

As a composer, Sakamoto Ryuichi has systematically studied Western traditional composition. In the film, Sakamoto Ryuichi adopts symphony style writing techniques to highlight the mood of the scenes. Still, the compositions are intertwined with melodies rich with characteristic sounds from Chinese national music. Due to the fusion between the orchestration of Chinese and Western styles, the composition is at times melancholy and obscure, meanwhile, it is also quite passionate at other times. It is an impressive theme song that conveys the feelings of the ups and downs (Bengtsson \& Gabrielsson, 1983)).

Among the two theme melodies with Chinese colours, the first theme melody is represented by the main melody of "FirstCoronation" (hereinafter referred to as melody A), and the second theme melody is represented by the main melody of "open the door" (hereinafter referred to as melody B). These two melodies are analysed in detail below.

In melody $\mathrm{A}$, the tortuous pentatonic melody line jumps upwards before transitioning downwards. In melody $\mathrm{B}$, the overall trend of the melody is downward. However, it rises again at the end. Occasionally, the ups and downs of the melody highlight the state of mind, indicating a glimmer of hope that is soon be extinguished. Furthermore, it also exaggerates the feelings of helplessness, depression, and epic and fateful sighs.

With regards to the orchestration, three elements were used for the main orchestration. Besides using Western string music to easily express emotions, Sakamoto Ryuichi selected the erhu with a bleak timbre and the pipa with a classical and sad tone. In addition, with the aid of the Guzheng and Dizi, the artist managed to embody the Chinese characteristics. The musical instruments support the most important emotional line in the music while rousing the emotions of all audiences (Hayter-Menzies \& Crossley, 2008).

\subsection{The appearance of the theme song variation from a historical and cultural perspective and the appreciation of Chinese and Western music elements.}

The film utilizes parallel montage and flashbacks to portray the life story of the protagonist $\mathrm{Pu} \mathrm{Yi}$.

It was previously mentioned that all plot scenes accompanied by this theme melody is tragic.

The first melody B appeared in the movie "open the door". The scene depicts a scenario where Pu Yi, who had become a prisoner in 1950, had committed suicide behind a closed door. Following the order of the officer to "open the door", another "door" in Pu Yi's life was recalled, which flashbacked his memory back in time to Beijing in 1908. This scene shows younger ones who were embracing at the entrance to the gate of the Forbidden City, and $\mathrm{Pu} \mathrm{Yi}$ was about to be appointed as a puppet emperor, the main reason for him to be crowned at such a young age was because Cixi did not want the imperial power to fall away. From that moment onwards, $\mathrm{Pu} \mathrm{Yi}$ led a tragic life. His tragic life is highlighted through the music that starts with a heavy orchestral western music, and a sharp pipa introduced with oriental elements in the middle. The orchestral music changes from a heavy atmosphere to a tense atmosphere. The first melody performed by a bleak erhu is accompanied with Chinese 
and Western blends. The sense of anxiety and oppression that is conveyed through the music hints at the precarious sadness and destiny of the Qing Dynasty (Thomas, 1991).

$\mathrm{Pu} \mathrm{Yi}$ was enthroned at a very young age, he was only 3 years old. The melody A "FirstCoronation" is heard for the first time during the enthroning scene. Following the introduction of the guzheng and flute, Chinese pipa and erhu were added to the theme melody, and the orchestral music was interwoven with Chinese national instruments. At this point, the spectacular sight of a hundred officials worshipping is reflected. The melody that contains sad emotions is a direct metaphor which indicates to the audience that the emperor is a puppet emperor at this stage, and the grandeur reveals sad and helpless emotions (Yoshiko, Sakuya \& Chang, 2015).

With the emergence of "Where is Armo"-the second variation of melody $\mathrm{B}$, the guard of honour of Yuan Shikai, the president of the Republic of China, who had entered the Forbidden City is portrayed in the film. The nurse who grew up with $\mathrm{Pu}$ Yi was also forced out of the palace. In comparison to the first appearance, the western instruments changed from a cello to violin unison, which is mixed with additional elements pertaining to the oriental style. The sad erhu tone, guzheng, and pipa, collectively play a sad melody, vividly rendering $\mathrm{Pu} \mathrm{Yi}$ (Bullerjahn and Güldenring, 1994)). The helpless situation highlights the feeling of confusion and incomprehension all around.

The second appearance of Melody A is heard during the scene that portrays the incident when Puyi learned of about his mother's suicide. He wanted to leave the premises and go out from the gate of the Forbidden City to visit his brother and deceased mother. However, the guards refused. He requested reasonably, yet his request was rejected, and in despair, he shouted "Open the door", alas, it was of no avail. During this scene, th violin-based depressive melody exaggerated the grief of the emperor who was imprisoned in the Forbidden City (Walsh, 2020). Similarly, in the subsequent plot, when $\mathrm{Pu} \mathrm{Yi}$ became a puppet of the Japanese after he was overthrown earlier in his life, he learned that his wife will be taken away forcibly, he urgently made way for her to leave. With the rapid preparation of strings, the door opened again. His imprisonment forced him to be separated from his relatives again, and he kept on muttering "open the door" and "open the door". During this scene, melody B was once more played with a violin, and the concert with the cello melody played in the form of tremolo, and this musical section perfectly conveys the helplessness to the audience, the music highlights the despair of a down-andout emperor that could not even be with his wife.

The most exciting aspect is the first sounding of the theme song containing two melodies. In the historical context of 1924, the commander-in-chief Feng Yuxiang, led his troops to initiate a coup, he surrounded the Forbidden City. The Republican government collapsed, and $\mathrm{Pu} \mathrm{Yi}$ along with his family was expelled from the Forbidden City. Historically, this was an important turning point, and it was also the first time $\mathrm{Pu} \mathrm{Yi}$ walked out of the Forbidden City, moving into another cage. The theme song sounded at this moment. The second melody repeated after the first melody, which contained a slightly harsh flute sound. During the repetition, there was a change from strengthening to slowing down, static, and then to a strengthening, stronger, magnificent, and grievous mood (Watson, 2013). It conveyed a strong sense of history.

When elderly $\mathrm{Pu}$ Yi returned to the Forbidden City as a tourist, he reflected on his life and on the disappearance of a generation of empires, he was filled with emotion. During this scene, the theme song sounded again, the first melody and the second melody were intertwined. During the course of this scene, the first melody was changed multiple times, and the orchestration of the main melody changed from a helpless violin at the beginning to the erhu like weeping, which rouses emotions within the listener. Heartstrings talk about despair, sadness, and changes from the erhu to a violin, and then the entire chapter is ended with the second melody of the vicissitudes of Sino-Western fusion symphony. The melancholy, sad, recurring theme song is a perfect illustration of $\mathrm{Pu}$ Yi's dramatic and tortuous life, additionally, it reflects on a bleak period in history.

\section{MUSIC APPRECIATION IN THE PLOT OF "CHINESE FEUDAL OLD SOCIAL CULTURE" EMBODIED IN THE FILM}

\subsection{The arranged marriage culture in Chinese feudal history and the collision of Chinese and Western social thoughts}

The background presented in "The Last Emperor" is the era when the Chinese feudal society was aligning with the Western society. Bertolucci, the director of Western vision, also focused on the expression and portrayal of the arranged marriage culture, which is unique to Chinese feudal history.

Throughout the Chinese feudal history, for more than two thousand years, parents have determined the marriage of their children. Giving birth was considered as the priority task for couples, which was followed by the family contribution to the economic development. Under these circumstances, the emotional affection between men and women was the least considered factor, and was even denied on certain occasions. It was generally regarded that the main reason for people to get married is to promote the family, pass on the line, and to continue the incense. For the parties involved in the marriage, this kind of marriage is an instrumental marriage, it has formed the marriage norms, such as "male dominates and female follower", "arranged", "bought and sold", and 
"obeyed" (Pisarev, 2016). In a marriage relationship, a woman must be permanent, subordinate, and dependent on a man. In contrast, a man cannot be specific, marry more than one female, and dominate the woman. The same is true for royal marriages. The emperor Ming got married, and the affairs of the imperial daughter's husband could be seen more clearly, which was already established as a rule of court marriage.

In Western society, free love is advocated, and in such circumstances, the perspective of the custom of arranged marriage sounds absurd and tragic. During the era when "The Last Emperor" occurred, Western thoughts were starting to influence Chinese society and the thinking pattern of Chinese citizens, and many were starting to explore social innovation. The film also tells the relevant plot centred around this perspective. Furthermore, the music that appears in the plot also renders these ideas perfectly.

\subsection{Appreciation of the plot and soundtrack of the emperor's selection of concubines in "The Last Emperor"}

In his autobiography, $\mathrm{Pu}$ Yi mentioned, "The First Half of My Life": "I have had four wives. According to the saying at the time, the four wives he was referring to were one queen, one concubine, and two nobles. In essence, none of them is my wife. I don't have a wife at all. All I have are decorations to solve different problems. Although each of them has different specific experiences, they are all victims of the same system (Pu, 1964). "

In "The Last Emperor", there is also a plot of a young $\mathrm{Pu} \mathrm{Yi}$ choosing a concubine. At the time, $\mathrm{Pu} \mathrm{Yi}$ was influenced by $\mathrm{Tu}$ Shidun, his teacher from the West. During this period, he opposed arranged marriages and disapproved polygamy. The soundtrack in $\mathrm{Pu}$ Yi's selection of concubine is also exaggerating this tradition, simultaneously, it ingeniously shows the reason for $\mathrm{Pu}$ Yi's psychological display.

In the scenes of the film, the selected show girls lined up, and the emperor who wants to love freely has to choose casually. During this scene, "Piking a Bride" by David Byrne sounded. The composer's melody adopts the Chinese five-tone mode, and the orchestration uses only Chinese traditional musical instruments. There is no involvement of western musical instruments, perhaps emphasizing the only feudal tradition in China. However, the genre is humorous and lively, adopting the electronic rhythm of western modern music. Following a few bars of percussion, the sound of the Chinese flute appears in a humorous image under the embellishment of the guzheng. Following this, the dulcimer appears, and the tone of the left-hand bass of the dulcimer ends. The tortuous melody line presents an upward trend, slightly repetitive, and is very expressive. The Chinese elements provide the audience with an antique feeling, illustrating the charm of the palace, and the style of the music is lively and funny, interesting, and, at the same time, ironic and absurd.

Following the conclusion of the wife selection plot, a dissatisfied $\mathrm{Pu}$ Yi complains to Johnston, not just about choosing one wife, but two, a queen and a noble concubine. When $\mathrm{Pu} \mathrm{Yi}$ asks Johnston which one, he would choose as the queen, $\mathrm{Pu} \mathrm{Yi}$ angrily said that it was not me who would choose, but they would choose. Obviously, the right one is contrary to his choice. He has been living under the arrangements and merchandise of others throughout his life, and does not have the independence to choose even during an important life event, such as marriage (Campbell \& Heller, 1980). The so-called emperor's choice of a wife is actually an internal decision, just a ritual for a charade. Such a plot can't help but make the audience recall the music that stopped abruptly with the ending of the wife selection, making them feel a touch of sadistic drama.

\subsection{Appreciation of the different fate and music of Wanrong and Wenxiu}

In relation to $\mathrm{Pu}$ Yi's main household Wanrong, and side household Wenxiu, they were both $\mathrm{Pu}$ Yi's people around him. However, one moved from openness to feudalism, and became a canary in a cage; while the other moved from feudalism to openness, and became a free bird. The completely different ending was embarrassing and filled with emotion. In addition, the contrasting soundtrack in the film exaggerates their different destinies.

Wanrong has been educated in Western thought. So, she held advanced ideological concepts. However, due to the identity of a queen, and in line with traditional thinking, she prioritized the identity of a "queen". Her family also needed a queen, even if she thinks of divorce, her family will be pressured and obstructed due to her own interests.

It is precisely due to the conservativeness and ignorance of such traditional feudal thoughts, that a woman who had been imprisoned by such feudal thoughts for a long time becomes addicted to drugs. During the last scene of the film, she has lived into a madness that even $\mathrm{Pu}$ Yi can hardly recognize (Boltz, Schulkind \& Kantra, 1991). During this scene, the helpless theme B melody reappears, and the aggressive performance marked a tragic fate for this character.

On the other hand, Wenxiu grew up in a traditional feudal family, and is logically the person who was the most deeply fettered by feudal rituals. However, in Puyi's autobiography, Wenxiu is once described: What is more valued is the idea of demanding freedom and the family life of an ordinary person. 
Historically, Wenxiu was influenced by Western thoughts, and no longer accepted polygamy, and boldly chose to publicly publish a divorce claim under the witness of the entire Chinese population, and announced that she had no relationship with Puyi.

In the artistically processed film, Wenxiu appealed to Puyi stating "I want a divorce" three times, and with each time, the appeal became stronger. However, right from the very beginning, Puyi dismissed it as a joke, and finally turned into helplessness after his anger.

As the melody of "Rain" sounded, this tense plot also ushered in a climax: Wenxiu ran out of the room excitedly, trotted downstairs after delivering the letter through the door, opened the door, and rushed out, regardless of the fact it is raining heavily.

The performance of the orchestra and the unison of the violin creates an emotional scene, exaggerating Wenxiu's inner determination. The violin melody rises in the form of two extremes, and then changes to a higher part. Seemingly, each time in unison, Wenxiu is further away from his free will.

Standing in the rain, Wenxiu takes the umbrella from the waiter and suddenly throws it away shouting: "I don't need it anymore!", this phrase has a deeper meaning, it implies that the protection of the role of husband in feudal marriages is no longer needed, the "Noble Concubine" is no longer needed (Moll-Murata, 2018). During the portrayal of this scene, the violin performing the ensemble becomes more determined and inspiring. With passionate string music, she broke through the shackles of ritual and music, and she used the method of divorce to move towards freedom and to start a new life, where she no longer feels restrained and controlled.

\section{ANALYSIS OF THE INTEGRATION OF CHINESE AND WESTERN MUSIC AND CULTURE FROM THE EXCERPTS OF FAMOUS CHINESE AND WESTERN MUSIC IN THE FILM}

\subsection{Film music and Chinese and Western music culture}

In addition to the original soundtrack created by the artists in "The Last Emperor", the appearance of some classic tracks in the film perfectly render the plot.

The film music creation team, including the director and those who worked on the soundtrack, conducted a considerable amount of preliminary research. As a part of this research and brainstorming, the team studied a large number of historical documents and studied the life of $\mathrm{Pu}$ $\mathrm{Yi}$ as well as the background of that era in detail. It also combines the culture, history, or emotions that the film wants to reflect and express. It introduces some musical ideas about this paragraph. According to the needs of the film plot, appropriate Chinese and Western classics could be selected or adapted (Lu, 1994). The perfect integration of itself and the soundtrack reflects the passion of the collision between Chinese and Western music styles and cultural perspectives.

\subsection{The adaptation and appreciation of "Auld lang syne"}

The most impressive thing about the music in the film is the appearance of "Auld lang syne" in one particular scene. When $\mathrm{Pu}$ Yi is sent off to the dock to bid goodbye and see off his mentor Johnston, a folk orchestra suddenly plays a blessing melody.

It is an old English song, originally from a 18th century Scottish peasant poet. Robert Burns recorded a poem according to the local elders. The name is "Auld lang syne". Later, this poem was composed into music. In addition to the original Scottish text, this song has also been adapted internationally in many countries. Throughout China, this song is commonly called "friendship all way long", symbolizing a goodbye or an ending filed with sadness and helplessness.

Since Johnston was from Scotland, this famous Scottish ballad was chosen to see him off in the film, and the orchestration was cleverly adapted. The small band hired by Puyi comprised of traditional national musical instruments, and is matched with traditional folk orchestra instruments, such as the Pipa, Sheng, Xiao, etc., playing a Scottish style melody. The delicate and euphemistic tone of Jinghu and Dizi are additional factors that better exaggerates the reluctance and sadness when $\mathrm{Pu} \mathrm{Yi}$ and Johnston parted. Moreover, the memory of this foreign teacher-student relationship and the feeling of sincere blessing to the teacher are highlighted.

A last emperor of China, a last emperor from Scotland, a folk band, and a western music fully demonstrated the resonance of Chinese and Western music culture.

\subsection{Appreciation and analysis of selected Chinese and Western music}

Undoubtedly, Johnston's upbringing in a western society had a huge influence on $\mathrm{Pu} \mathrm{Yi}$. Johnston influenced $\mathrm{Pu}$ Yi with advanced Western thoughts, and he introduced modern science concepts into the Forbidden City. This exposed $\mathrm{Pu} \mathrm{Yi}$ to new ways of thinking and accepting Western cultural thoughts. It was a completely new experience for $\mathrm{Pu} \mathrm{Yi}$, who had been in a closed palace since childhood. The edification also brought a new atmosphere to the ancient palace.

The film contains an intriguing scene before the classic scene where Puyi cuts off his braids and aspires to reform. The film shows a scene where, in the quaint Forbidden City, Pu Yi's younger brother Pu Jie is seen to 
be practicing a violin, meanwhile, $\mathrm{Pu}$ Yi's two wives, Wan Rong and Wen Xiu, rest aside. Pu Jie played the melody of "Minuet in G Major" composed by Beethoven. Minuet music was popular in Western court and aristocratic society. The music was quite often used in accompanying dances, and it was also quite appreciative. Beethoven's minuet music was even livelier, and it was regarded with immense popularity in the Western society. As a result, Johnston who was passing by could not help but hum happily. And because of the unique musical quality of the minuet, Wanrong and Wenxiu also started to dance together, they danced the cha-cha with each other. The two dressed in traditional Qing dynasty costumes, seemed incompatible with Western dance and music, nevertheless, the scene shows that they enjoyed it. However, the conserved old palace ladies passing by scoffed at their behavior, which contrasted with Johnston's attitude.

In addition to the famous Western songs mentioned above, the two appearances of "The Moon in Two Springs" selected by the Chinese composer Su Cong also sublimates the content of the film. "Er Spring Reflected in the Moon", is a famous erhu song composed by the blind Chinese artist, A Bing. It expresses the thoughts and emotions of a blind artist who has experienced the bitterness and pain of the world from beginning to end.

As Puyi and other war criminals watched a documentary about the Japanese invasion of China in the probation centre, Puyi started to gradually realize that he was not only a victim, but also a member of the culprit. The bloody disasters and persecutions suffered by the Chinese people in the documentary shocked him even more. During this scene, the sound of the traditional Chinese folk music "The Second Spring Reflected in the Moon" metaphorizes the shame and suffering that had become a part of China. The inner forbearance combined with the heavy and solemn melody also underpins Pu Yi's inner high indignation, sadness, and resentment.

The second appearance is at the end of the film. $\mathrm{Pu}$ $\mathrm{Yi}$, who is nearly sixty years old, once again returns to the former residence of the Forbidden City. As he ambles past the empty Forbidden City without any tourists in the scenic spot, the melody of "Two Springs Reflected in the Moon" is sounded. This classic national tune reflected the traditional simplicity of the Forbidden City, and the melancholy and sentimental contained in the music combined with the deserted Forbidden City perfectly renders Pu Yi's inner emptiness (Loshitzky, Meyuhas \& Bertolucci, 1992). He reflects on the ups and downs in his as a puppet ruler, through the sadness, a slight feeling of content is expressed, and the music conveys $\mathrm{Pu}$ Yi's emotions about his life to the audience.

\section{CONCLUSION}

Through the form of Chinese and Western fusion, In "The Last Emperor", the Chinese and Western coproduced film work, the soundtrack is innovative and appreciative, while adding more interpretation, more in line with the plot of the film. Whether it is Western music or Chinese traditional music, there is a profound background. On the basis of inheriting a long history of music culture, constantly seeking breakthroughs, integrating Chinese and Western music cultures, and learning from each other in Chinese and Western aesthetics, the music language of international music creation and communication shall yield unusually brilliant results.

\section{REFERENCES}

[1] Bengtsson, I. \& Gabrielsson, A. (1983). Analysis and synthesis of musical rhythm. In Studies of music performance (ed. J.Sundberg), pp. 27-60. Royal Swedish Academy of Music, Stockholm.

[2] Boltz, M., Schulkind, M., \& Kantra, S. (1991). Effects of background music on the remembering of filmed events. Memory and Cognition, 19, 593-606.

[3] Brown, R. (1988). Film and classical music. In Film and the arts in symbiosis: A resource guide (ed. G.R. Edgerton), pp. 165-215. New York, Greenwood Press.

[4] Bullerjahn, C. and Güldenring, M. (1994). An empirical investigation of effects of film music using qualitative content analysis. Psychomusicology, 13, 99-118.

[5] Burt, G. (1994). The art of film music. Northeastern University Press, Boston, MA.

[6] Campbell W. \& Heller, J. (1980). An orientation for considering models of musical behavior. In Handbook of music psychology (ed. D. Hodges), pp. 29-36. National Association for Music Therapy, Lawrence, KS.

[7] Chion, M. (1994). Audio-vision: Sound on screen (C. Gorbman, Trans.). Columbia University Press, New York. (Original work published in 1990)

[8] Clarke, E. (1988). Generative principles in music performance. In Generative processes in music, (ed. J.A. Sloboda), pp. 1-26. Clarendon Press, Oxford.

[9] Hayter-Menzies, G., \& Crossley, P. (2008). China reborn. In Imperial Masquerade: The Legend of Princess Der Ling (pp. 313-320). Hong Kong University Press.

[10] Kehr, D. (1999). BESIEGED. Film Comment, 35(2), 6-8. Retrieved October 26, 2020. 
[11] Loshitzky, Y., Meyuhas, R., \& Bertolucci. (1992). "Ecstasy of Difference": Bertolucci's "The Last Emperor". Cinema Journal, 31(2), 26-44.

[12] Lu, J. (1994). "The Last Emperor": A "History Lesson" and a Lesson in History. Biography, 17(1), 56-62. Retrieved October 26, 2020.

[13] MOUTON, J. (1992). THE LAST EMPEROR: A Subject-in-the-Making. In DICK B. (Ed.), Columbia Pictures: Portrait of a Studio (pp. 218-230). University Press of Kentucky. Retrieved October 26, 2020.

[14] Pu, Y. (1964). The first half of my life. Beijing: Mass Publishing House. 304pp.

[15] Pisarev, A. (2016). Soviet Sinology: Two Conflicting Paradigms of Chinese History. In Shih C. (Ed.), Sinology in Post-Communist States: Views from the Czech Republic, Mongolia, Poland, and Russia (pp. 115-132). Sha Tin, N.T., Hong Kong: The Chinese University of Hong Kong Press.

[16] Storaro, V., \& Rutter, C. (1989). Colorific: Vittorio Storaro. Film Comment, 25(5), 46-50. Retrieved October 26, 2020.

[17] Thayer, J. F., \& Levenson, R. W. (1983). Effects of music on psychophysiological responses to a stressful film. Psychomusicology, 3, 44-52.

[18] Thomas, Tony. (1991). Film score: the art \& craft of movie music. Burbank, Calif.: Riverwood Press.

[19] Walsh, M. (2020). Contact. In Stating the Sacred: Religion, China, and the Formation of the NationState (pp. 109-132). New York: Columbia University Press.

[20] Watson, B. (2013). FIT FOR EMPERORS AND KINGS. In The Complete Works of Zhuangzi (pp. 55-59). NEW YORK: Columbia University Press.

[21] Yoshiko, Y., Sakuya, F., \& Chang, C. (2015). The Nichigeki Incident. In Fragrant Orchid: The Story of My Early Life (pp. 113-130). University of Hawai'i Press. 